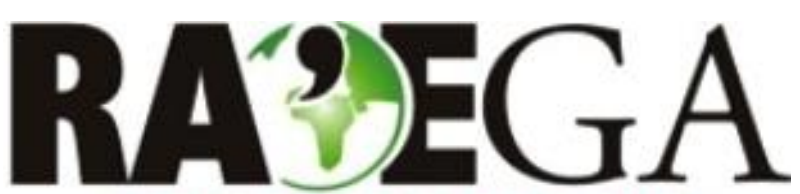

O ESPAÇO GEOGRÁFICO EM ANÁLISE

\title{
CARACTERIZAÇÃO DO TORNADO OCORRIDO EM MARECHAL CÂNDIDO RONDON E QUATRO PONTES EM NOVEMBRO DE 2015
}

\section{CHARACTERIZATION OF THE TORNADOE OCCURRED IN MARECHAL CÂNDIDO RONDON AND QUATRO PONTES IN NOVEMBER 2015}

\author{
Karin Linete Hornes ${ }^{1}$, Marcos Balicki ${ }^{2}$
}

RESUMO

O tornado é um dos fenômenos atmosféricos mais severos que existem na natureza, apesar de sua rápida atuação de tempo e espaço, causam grandes prejuízos por onde passam. No Brasil a atuação destes é bastante significativa deixando o país em segundo lugar no ranking mundial. No entanto o desempenho destes fenômenos é pouco descrito e divulgado, uma vez que não existe no país um órgão específico para o acompanhamento destes eventos. Neste sentido o presente artigo tem por objetivo a caracterização da ocorrência de um tornado de múltiplos vórtices ocorrido nos municípios paranaenses de Marechal Cândido Rondon e Quatro Pontes no dia 19 de novembro de 2015. Com o intuito de caracterizar a situação atmosférica e a extensão percorrida pelo fenômeno. Para a caracterização da tormenta, foram realizadas análises em imagens de radar, de satélite Goes e em conjunto com atividades de campo, foi possível elencar alguns elementos envolvidos na atuação desse tornado e sua dinâmica destrutiva. Na conclusão deste artigo foi possível definir o tipo de tornado ocorrido, bem como averiguar os elementos climáticos envolvidos em conjunto com o nível de destruição ocorrido. Ao término foram realizadas propostas de atividades que auxiliem a monitoração de alguns elementos que podem dar origem ao episódios severos e que permitam verificar e relacionar com semelhantes eventos futuros.

Palavras-chave: Tornado; múltiplos vórtices; radar; supercélulas, desastre.

\section{ABSTRACT}

The tornado is one of the most severe atmospheric phenomena that exist in nature, despite its rapid performance of time and space, cause great damage wherever they go. In Brazil the performance of these is quite significant leaving the country in second place in the world ranking. However the performance of these phenomena is little described and disclosed, since there is no specific department in the country to follow up on these events. In this sense, this article aims to characterize the occurrence of a multiple vortex tornado occurred in the municipalities of Marechal Cândido Rondon and Quatro Pontes on November 19, 2015. In order to characterize the atmospheric situation and the extent covered by the phenomenon. For the characterization of the storm, analyzes were performed on radar images from Goes satellite and in conjunction with field activities, it was possible to list some elements involved in the performance of this tornado and its destructive dynamics. At the conclusion of this article it was possible to define the type of tornado occurred, as well as to ascertain the climatic elements involved in conjunction with the level of destruction occurred. At the end, proposals were made for activities that help to monitor some elements that may give rise to the severe episode and that allow to verify and relate with similar future events.

Key-words: Tornadoe; multiple vortices; radar; Supercells, disaster

Recebido em: 19/07/2016

Aceito em: 12/06/2017

\footnotetext{
${ }^{1}$ Universidade Estadual do Oeste do Paraná, Marechal Cândido Rondon, e-mail: marcosbalicki88@gmail.com

${ }^{2}$ Universidade Estadual do Oeste do Paraná, Marechal Cândido Rondon, e-mail: marcosbalicki88@gmail.com
} 


\section{CARACTERIZAÇÃO DO TORNADO OCORRIDO EM MARECHAL CÂNDIDO RONDON E QUATRO PONTES EM NOVEMBRO DE 2015}

\section{INTRODUÇ̃̃O}

O tornado é um acontecimento atmosférico que se manifesta através de um vórtice de ar que gira de forma violenta, estando em contato com uma nuvem e com qualquer estrutura da superfície terrestre. Eles podem ter centenas de metros de diâmetro e se manifestam de diversas formas e tamanhos, normalmente se formam associados a variações de temperatura que produzem ventos fortes, elevada precipitação pluviométrica e frequentemente presença de granizo (PERUZZO, 2013, pg.261). A formação de tornados está ligada a interações existentes entre fortes fluxos de ar ascendentes e descentes que propiciam uma movimentação intensa dentro da nuvem (PERUZZO, 2013, pg.261).

Uma das principais dificuldades com registro e evidência de tornados é a necessidade de observação do fenômeno. Ao contrário da precipitação ou da temperatura que podem ser medidas por instrumentos fixos, o tornado torna-se um desafio para os aparelhos atuais, por apresentar uma curta duração e atuar em uma dinâmica espacial considerada uma incógnita. Assim, registros dos fenômenos tendem a ocorrer em sua grande maioria com fotografias e filmagens onde há maiores aglomerações humanas. Em locais de baixa densidade demográfica o mesmo dificilmente será documentado, desta forma muitos tornados deixam de ser registrados.

O fenômeno especificamente ocorrido em Marechal Cândido Rondon foi confirmado pelo Instituto de tecnologia, SIMEPAR (Sistema Meteorológico do Paraná) e trouxe muita destruição. Como ainda não foi realizado nenhum estudo a respeito das especificidades de sua atuação, pretende-se nesta pesquisa elaborar uma caracterização quanto à situação do tempo no momento de sua ocorrência; descrever o percurso que o mesmo apresentou reconhecer e descrever a força destrutiva ocorrida no momento de sua atuação e divulgar as dinâmicas envolvidas, com o propósito de fortalecer pesquisas que se dediquem a prevenção e registro de tornados. Espera-se que o trabalho possa contribuir com a defesa civil e a organização dos municípios no que se diz respeito ao planejamento e organização das cidades para que ocorrências de situações de tempo severo como esta ou semelhantes (vendaval) não venham causar tantos prejuízos.

Como um sistema preventivo no momento atual ainda não é muito bem definido no Brasil é importante caracterizar e discutir a atuação dos tornados e os problemas socioambientais ocorridos, pois assim será possível traçar estratégias de organização política, social e econômica que podem tornar as cidades mais resilientes e seguras a este tipo de desastre.

\section{MATERIAIS E MÉTODO}

A presente pesquisa foi concebida a partir do embasamento teórico metodológico sobre tornados presentes nos autores como Doswell (1996), Marcelino (2007), Cândido (2012, 2016), Bertoni et. al (2013) entre outros, que discutem as formas de atuação tornádica, tipo de nuvens e atividades de frentes envolvidas na sua gênese (MARCELINO, 2003). Após deu-se início a pesquisas a respeito do período e local onde estes eventos acabam atuando nos Estados Unidos, fazendo um comparativo com o que ocorreu em Marechal Cândido Rondon. Verificou-se também os horários de maior atuação destes fenômenos e a dinâmica climática envolvida de vários elementos tais como pressão, temperatura, massas de ar entre outros. Além do levantamento de informações a respeito do tipo, classificação, comportamento e deslocamento da célula tornádica para compreensão do evento ocorrido.

De posse destas informações deu-se início a visualização de inúmeras fotos, vídeos e reportagens disponíveis na internet. Posteriormente a estas visualizações, iniciou-se as atividades de campo que primaram por realizar o traçado do tornado e a verificação de sua destruição. As atividades de campo foram 


\section{CARACTERIZAÇÃO DO TORNADO OCORRIDO EM MARECHAL CÂNDIDO RONDON E QUATRO PONTES EM NOVEMBRO DE 2015}

realizadas entre os dias 19 de novembro de 2015 a 30 de abril de 2016. Foram realizados 389 questionários e visitadas aos afetados do percurso envolvendo estruturas localizadas na área rural e urbana dos municípios. As coordenadas foram pontuadas através da utilização do GPS Garmin (GARMIN-ETREX LEGEND C). Quando possível, entrevistou-se os moradores a respeito do que ocorreu com suas residências e do que os mesmos vivenciaram naquele dia. Todas as entrevistas e questionários foram realizadas com a devida documentação e permissão dos interrogados.

Após a tabulação de dados e com a plotagem dos pontos georreferenciados foi possível calcular a largura a aproximada do funil do tornado principal e o trajeto percorrido, bem como definir os diferentes níveis de intensidade de destruição. Os níveis de intensidade de destruição foram determinados da seguinte forma: 0 sem danos; 1 galhos quebrados; 2 Destelhamento parcial com caules quebrados, descascados e postes inclinados; 3 telhados inteiros, arrancados, árvores arrancadas pela raiz, postes quebrados; 4 Carro arrastado por poucos metros; caminhão e ônibus tombado; estruturas totalmente destruídas como: Residências, barracões e silos. $\mathrm{Na}$ Escala Fujita o 0 corresponderia ao EF0; 1 e 2 ao EF1, 3 e 4 ao EF2 Estes níveis foram definidos especialmente para a presente pesquisa, e foram pensados a partir da Escala Fujita Melhorada e adaptados para o tipo de destruição ocorrida em Marechal C Rondon. Assim foi possível construir o mapa de níveis de destruição realizado no Arc Gis. Após a realização desta etapa os mapas foram construídos com o auxílio do programa Google Earth, Google Map, CorelDraw X5 e Global Mapper 15. Em paralelo deu-se início a busca dos dados meteorológicos e das imagens de radar e satélite para a verificação dos elementos climáticos envolvidos na atuação. De posse destes dados construiu-se o presente texto.

\section{RESULTADOS E DISCUSSÃ}

Tornados são eventos climáticos que ocorrem naturalmente em todo o mundo onde se desenvolvem grandes nuvens de tempestades. Eles são um dos eventos atmosféricos mais ferozes que existem na natureza, gerando danos socioeconômicos de grandes proporções e que podem ser considerados como desastres naturais (ALCÁNTARA-AYALA, 2002 apud BERTONI, 2012).

No Brasil, as ocorrências se dão principalmente na região Sul, Sudeste e CentroOeste (MARCELINO, 2003) principalmente em estações de transição (primavera e outono). $\mathrm{Na}$ região centro-sul os tornados se formam no avanço de frentes frias e secas da Antártida (Massa Polar Antártica) (sul), com o ar quente e úmido da Amazônia (Massa continental equatorial) (norte) e massa continental tropical (Chaco) (oeste) (MARCELINO, 2003), que sobre - Estado do Paraná, formam núcleos de precipitação frontal. Estes podem evoluir a grandes nuvens de desenvolvimento vertical e provocar os tornados. No entanto, o reconhecimento do fenômeno é difícil de ser realizado sem as evidências visuais, pois o mesmo pode ser confundido com outros fenômenos que causam destruições semelhantes. Como os Downbursts ou micro explosões. Esta ultima é caracterizada por uma descida rápida de grandes volumes de ar mais denso (frio e pesado) do interior de uma nuvem Cumulonimbus (Cbs), causando na área atingida uma destruição em forma circular ou radial (CLIMATEMPO, 2016). A destruição é "semelhante" a causada por um tornado no entanto seu efeito se restringe a apenas $4 \mathrm{~km}$ (quilômetros) de diâmetro (CLIMATEMPO, 2016).

O Tornado, segundo Kobiyama et al (2006), é definido como uma coluna giratória de ar, geralmente visivel e em forma de "funil", que desce da base de uma grande nuvem até causar danos em superfície. Esta grande nuvem, de acordo com o Glossário de Meteorologia (HUSHCKE,1959) é denominada 


\section{CARACTERIZAÇÃO DO TORNADO OCORRIDO EM MARECHAL CÂNDIDO RONDON E QUATRO PONTES EM NOVEMBRO DE 2015}

de Cúmulo-nimbo (Cbs) de rápido desenvolvimento vertical (Figura 1). Com base de 2 a $10 \mathrm{~km}$ de diâmetro (base da nuvem em forma de parede). Esta nuvem se caracteriza pela presença de uma "torre" com "bigorna" e por correntes ascendentes quentes (baixa pressão/influxo) e descendentes frias (alta pressão/afluxo) que podem proporcionar no interior desta um sistema espiral e cilíndrico chamado de mesociclone ou vortex de ciclone (Figura 1). Esse mesociclone gira e é alimentado por essas correntes. Dentro do mesociclone as correntes podem alongar-se como um funil até tocar a superfície (DOSWELL,1996) formando o tornado (Figura 1).

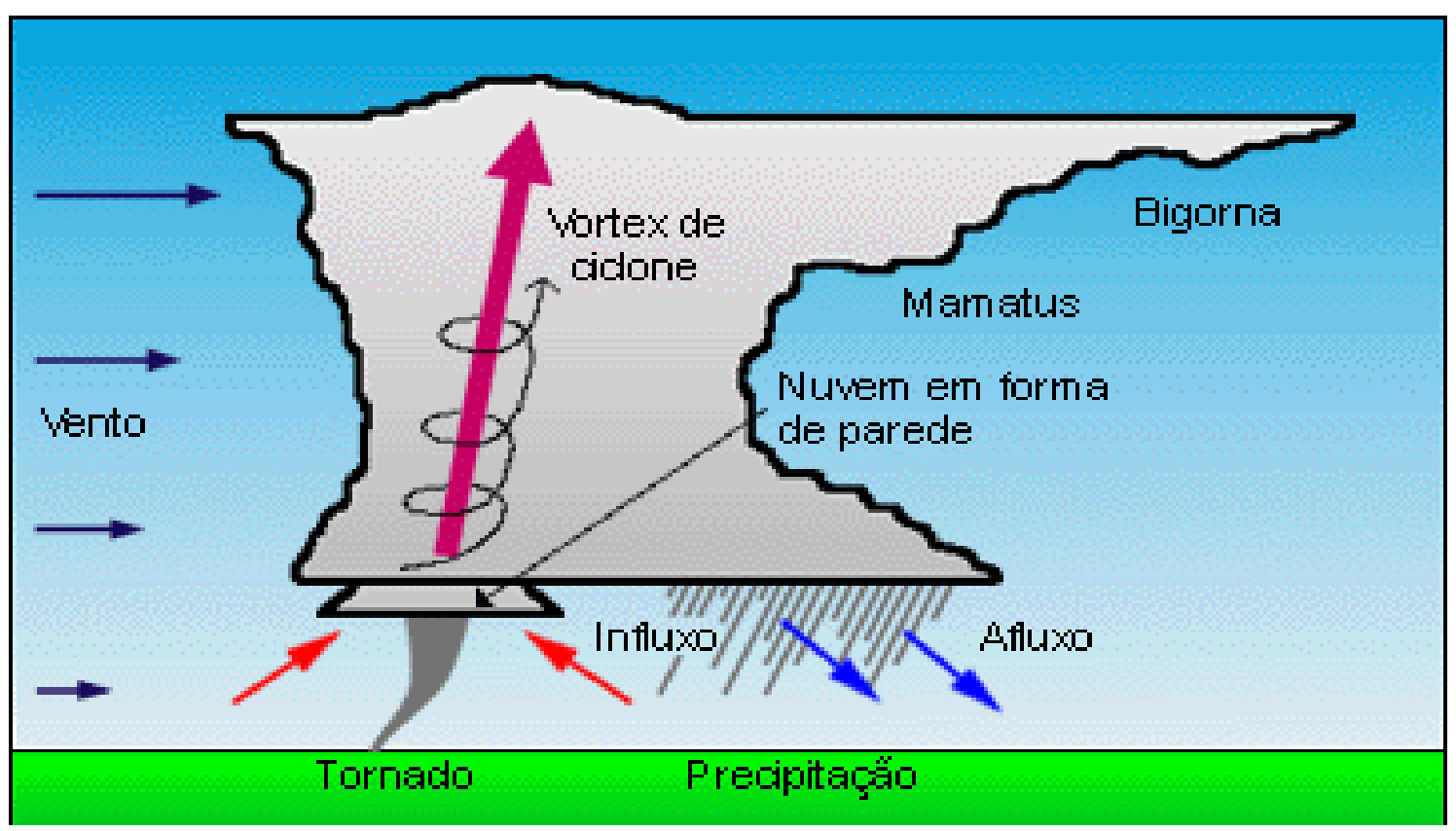

Figura 1 - Perfil esquemático de uma nuvem Cúmulo-nimbo com tornado. Fonte: Dammous (2015).

Alguns lugares do mundo são mais propícios a formação de nuvens capazes de gerar tornados. Os locais que mais registram o fenômeno se localizam no meio oeste dos Estados Unidos (Figura 2) principalmente no vale do Rio Mississipi, também chamado de Corredor dos Tornados (Tornado Alley), onde tempestades tornádicas se formam pelo choque térmico das correntes do golfo (ar quente e úmido) com a corrente de ar das Montanhas Rochosas (frio e seco), e as nuvens geralmente seguem em direção a nordeste
(INPE, 2015). Essa região é de clima tipicamente Semi-Árido a Subtropical, com vegetação tipo floresta temperada/subtropical, pradarias e estepes (VEDOVATE, 2010), com altitude média do platô de 200 a 800 metros (BARRY e CHORLEY, 2013). Nota-se que a região centrosul do país (Brasil) também foi incluída como região propensa a atividade (Figura 2). Destacase ainda que o clima, altitude e vegetação das áreas mais afetadas na América do Sul se assemelham grandemente ao que se sucede nos corredor dos tornados. 


\section{CARACTERIZAÇÃO DO TORNADO OCORRIDO EM MARECHAL CÂNDIDO RONDON E QUATRO PONTES EM NOVEMBRO DE 2015}

MAPA DE FREQUÊNCIA DE TORNADOS

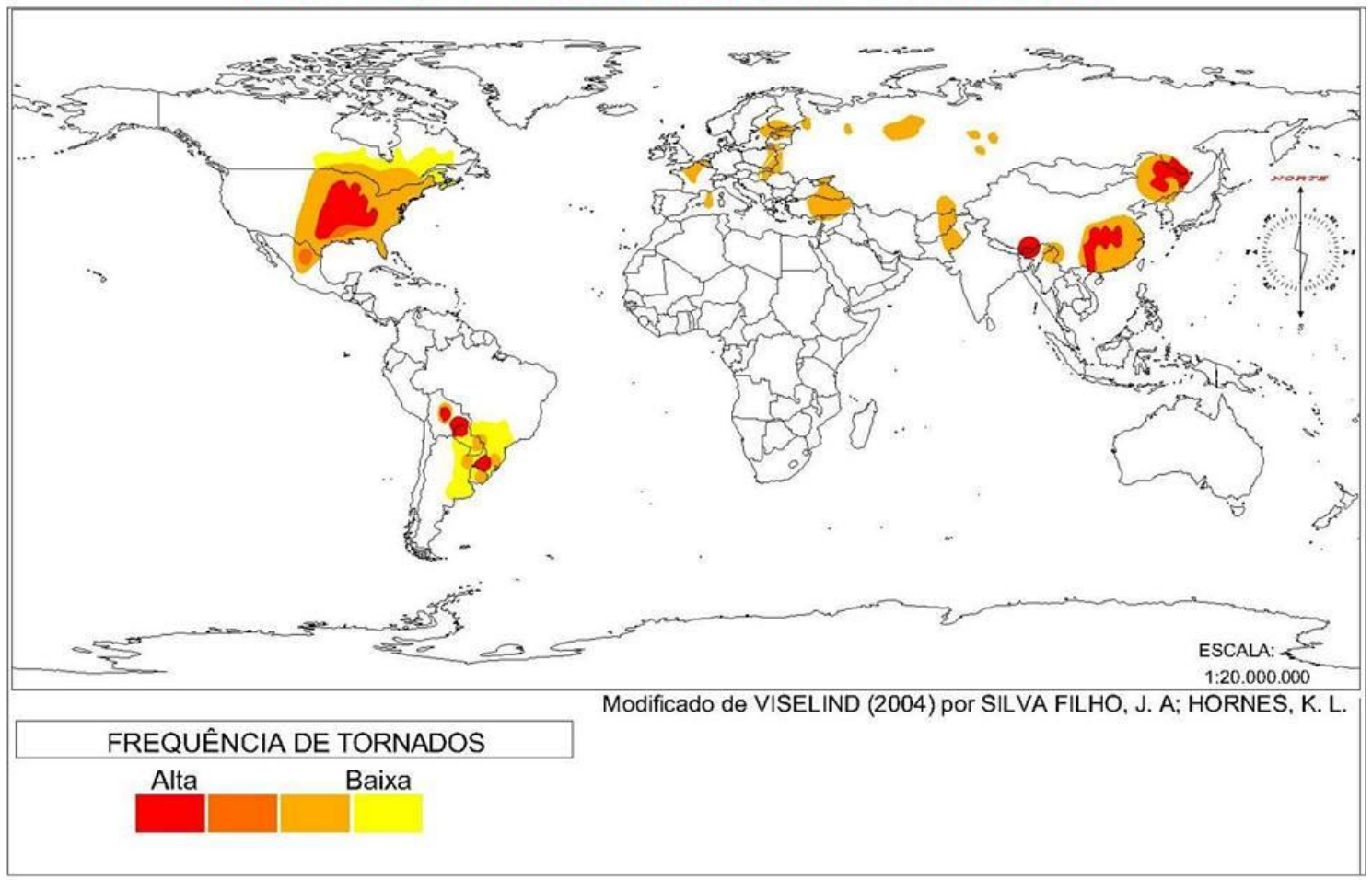

Figura 2 - Mapa de áreas de risco de tornados pelo mundo. Fonte: Vesilind (2004).

Confome informações do NOAA (2016) em todos os meses do período de 1991 a 2010 foram registrados tornados, no entanto há uma maior concentração durante os meses de abril, maio, junho e julho, que correspondem aos meses de primavera no hemisferio Norte.

O horário de maior frequência de tornados ocorrem nas primeiras horas da tarde e à noite, com uma assiduidade mínima de madrugada, quando as temperaturas são mais baixas e os déficits de radiação são mais altos (NOAA, 2016). Isto ocorre porque a energia de aquecimento solar e calor latente são liberados pela condensação de vapor de água (NOAA, 2016) o que auxilia na instabilidade $e$ crescimento de nuvens super células (ou cúmulo nimbos).

O centro-sul do Brasil fica no segundo lugar com maior registros de tornados, conforme estudos elaborados por Daniel Cândido (2012). Ele catalogou 205 incidências de tornados de 1990 a 2011 em território nacional. Para este registro Cândido (2012) considerou somente os tornados efetivamente registrados através da coleta de fotos, jornais e revistas, entrevistas com moradores (questionários) e pesquisas na internet. $\mathrm{O}$ autor coloca que é possível que outros tenham ocorrido no período, no entanto não foram vistos ou não causaram danos significativos, ou foram confundidos ou incluídos como se fossem ventanias ou tempestades, ressalta 0 geógrafo. O Atlas de desastres naturais do Brasil (2012) catalogou 41 tornados de grandes proporções de 1990 a 2010, no entanto estes registros contabilizaram apenas os que proporcionaram grandes destruições.

Segundo Barry e Chorley (2013, Pag. 254), nas planícies americanas, os tornados costumam se desenvolver dentro de sistemas convectivos de mesoescala, geralmente de formações por agrupamento de células isoladas de cúmulos-nimbos, que junto formam esse grande sistema, gerando tempo severo. Silva Dias, (1996 apud Kobiyama et al, 2006), afirmam que Complexos Convectivos de Mesoescala são sistemas com intensidade suficiente para gerar chuvas fortes, ventos, granizo e tornados; na América do Sul esses sistemas formam-se geralmente no norte da 


\section{CARACTERIZAÇÃO DO TORNADO OCORRIDO EM MARECHAL CÂNDIDO RONDON E QUATRO PONTES EM NOVEMBRO DE 2015}

Argentina e Paraguai (região do Chaco) e nas regiões sul e sudeste do Brasil e deslocam-se em direção a sudeste, leste e nordeste (VESILIND, 2004).

Essas células se desenvolvem principalmente de 3 formas: sistemas convectivos lineares (em linha), sistemas convectivos em oclusão (cresce individualmente) e sistemas convectivos caóticos (crescimento pela junção de células menores) (BLANCHARD 1990, apud BARRY E CHORLEY, 2013, pag.255). Nessa perspectiva, células podem agrupar-se ao longo da frente da alta superficial e durante a formação de novas células, podem ocorrer tornados pela interação próxima das correntes frias descendentes (afluxo) e ascendentes (influxo) (BARRY e CHORLEY, 2013).

\subsection{TIPOS DE TORNADOS}

Com relação à gênese eles podem ser formados a partir de super-células ou na ausência delas (NSSL/NOAA, 2016) eles são classificados em tornados, trombas d'água (Waterspouts, tornados formados sob a água), Tornados de fogo (Fire tornadoes) e tornados de poeira (Dust Devil). Trombas D'água: As trombas d'água ocorrem sobre as águas e sua formação é muito semelhante à dos tornados, também podem ser chamados de watherpoust e sua força é difícil de ser medida, visto que a grande maioria ocorre no interior dos oceanos (NOAA, 2015), mas podem também atuar em superfícies costeiras, rios e lagos e causar prejuízos. Com relação ao tipo e número de vórtices estes podem se apresentar como:

Tornados gêmeos: Barry e Chorley (2013, p.261) afirmam que quando linhas de tempestades se formam sobre áreas extensas podem ocorrer vários deles, eles se formam num mesmo sistema de mesoescala ao mesmo tempo, ao longo de caminhos retos e cada qual possuí o seu mesociclone.

Tornado de múltiplos vórtices (Multivortex): Esses tornados são muito raros, segundo Barry e Chorley (2013, p.260), e muito intensos podendo gerar múltiplos vórtices girando dentro do tornado principal, no entanto não são claramente visíveis (NOAA 2016). Tal evento até então observado nos EUA, foi registrado no Brasil na cidade paulista de Indaiatuba, no dia 24 de maio de 2005 (NASCIMENTO et. al, 2015). Este tornado se caracteriza por possuir uma pressão extremamente baixa no seu interior e por apresentar vários vórtices que surgem e desaparecem no entorno do tornado principal (Figura 3). Segundo Barry e Chorley (2013, pág. 261), estes vórtices giram todos em um centro comum durante o deslocamento. O tornado de múltiplos vórtices é considerado um tornado de funcionamento complexo, pois existe uma disputa de espaço e energia entre os vórtices. Os vórtices de sucção podem adicionar mais de $160 \mathrm{~km}$ de velocidade (NOAA 2016). Como resultado, eles são responsáveis pela maioria (se não todos) casos em que o arco estreito de destruição extrema se encontram junto à danos fracos no contexto do caminho do tornado. Os sub-vórtices ocorrem geralmente em grupos de 2 a 5 de uma só vez sendo raros os que apresentam um número de vórtices entre 6 ou 7. Estes sub-vórtices geralmente duram menos de um minuto cada. Acredita-se que a maioria dos relatos de vários tornados de uma só vez (família de tornados) devem-se a ação de tornados de múltiplo vórtices. No entanto, em raras ocasiões, tornados independentes podem se formar perto um do outro, como tornados satélite (NOAA, 2016). 


\section{CARACTERIZAÇÃO DO TORNADO OCORRIDO EM MARECHAL CÂNDIDO RONDON E QUATRO PONTES EM NOVEMBRO DE 2015}

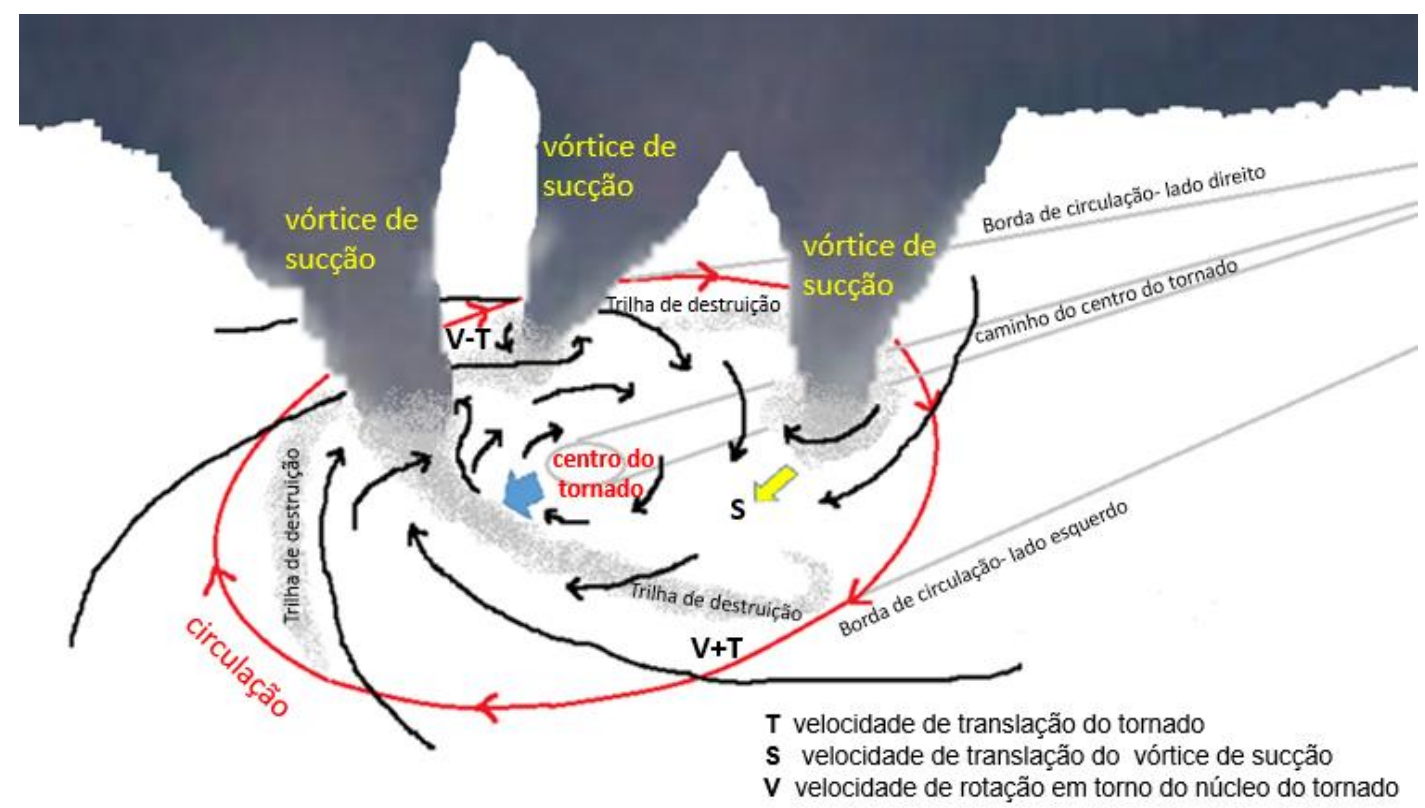

Figura 3 - Dinâmica de um tornado múltiplo vórtices. Fonte: Fujita et. al 1971; citado por Barry e Chorley (2013), adaptado pelo autor para o hemisfério sul.

Tornado Satélite: Segundo Barry e Chorley (2013), o mesociclone reduz seu diâmetro e a conservação do momento acelera a velocidade do vento. Em um determinado momento, às vezes, um tornado com vórtices secundários e em geral menores, orbitam em sentido contrário e a uma certa distância do tornado principal.

Landspout: São tornados sem a presença do mesociclone (NOAA, 2016). Em geral estreitos e muito mais fracos. Podem se formar de nuvens cúmulos e cúmulos-nimbos de rápido desenvolvimento vertical. Sua dinâmica funcional é muito parecida com as Trombas d'água, porém acontecem sobre a superfície (INPE, 2016).

Conforme a figura (4) a seguir, a corrente úmida e fria da parte traseira da nuvem super-célula, mistura-se a corrente de elevação frontal de evaporação (quente e úmida), aglutinando rapidamente e formando novas nuvens visíveis (flanco ou cauda).

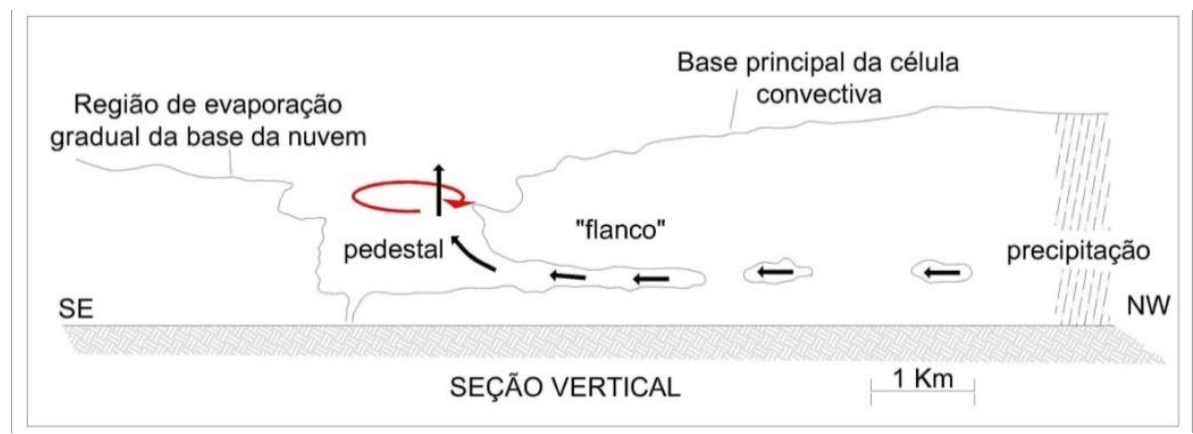

Figura 4 - Esquema lateral de uma super-célula tornádica. Fonte: Adaptado por HORNES (2017) de Fujita et. al (1976).

Estes sistemas alimentados pelas correntes horizontais e verticais formam um mesociclone, promovendo o giro, e por estarem próximas da superfície, formam um sistema em rotação (nuvens pedestal e rebaixamento), que é capaz de promover rapidamente tornados que tocam a superfície. $\mathrm{O}$ giro do redemoinho recebe interferências do 


\section{CARACTERIZAÇÃO DO TORNADO OCORRIDO EM MARECHAL CÂNDIDO RONDON E QUATRO PONTES EM NOVEMBRO DE 2015}

efeito de Coriolis. O efeito de Coriolis conforme Martins et. al (2008), promove o giro de tornados no sentido horário no hemisfério sul e anti-horário no hemisfério norte.

\subsection{ESCALA FUJITA}

A Escala Fujita foi inventada pelo Dr. Tetsuya Theodore Fujita em 1971 para classificar os tornados pelos danos da destruição causada em superfície. A partir desta escala tem-se a estimativa da velocidade dos ventos. No entanto em 2007 os cientistas aprimoraram a escala Fujita através de testes com vários tipos de estrutura assim foi desenvolvida a escala Fujita Melhorada (Quadro 1), com classificação em EFO à EF5 (Enhance Fujite Scale). Para a presente classificação de força destrutiva apenas a Escala Fujita Melhorada será considerada.

Tabela 1 - Escala Fujita Melhorada ou reforçada- EF. Fonte: Adaptado de Christopherson, 2012

\begin{tabular}{l|l|l}
\multicolumn{1}{c|}{$\begin{array}{c}\text { ESCALA } \\
\text { MELHORADA }\end{array}$} & \multicolumn{1}{c}{$\begin{array}{c}\text { VELOCIDADE DE RAJADAS EM } \\
\text { KM/H }\end{array}$} & \multicolumn{1}{c}{ DESCRIçÃo Dos DANOS } \\
\hline EF0 LEVE & $105-137 \mathrm{~km} / \mathrm{h}$ & $\begin{array}{l}\text { Danos leves: galhos quebrados, chaminés } \\
\text { danificadas. }\end{array}$ \\
\hline EF1 FRACO & $138-177 \mathrm{~km} / \mathrm{h}$ & $\begin{array}{l}\text { Danos moderados: início da designação de } \\
\text { velocidade de vento de furacão, materiais de } \\
\text { telhados saem do lugar casas móveis (trailer) } \\
\text { têm sua fundação deslocada. }\end{array}$ \\
\hline EF2 FORTE & $178-217 \mathrm{~km} / \mathrm{h}$ & $\begin{array}{l}\text { Danos consideráveis: telhados inteiros são } \\
\text { arrancados de casas de madeira, árvores } \\
\text { grandes e bem enraizadas são arrancadas, } \\
\text { vagões são deslocados, pequenos objetos } \\
\text { podem se tornar projéteis. }\end{array}$ \\
\hline EF3 SEVERO & $218-233 \mathrm{~km} / \mathrm{h}$ & $\begin{array}{l}\text { Danos severos: telhados são arrancados de } \\
\text { casas bem construídas, árvores são } \\
\text { desenraizadas, carros são arremessados. }\end{array}$ \\
\hline EF4 DEVASTADOR & $267-322 \mathrm{~km} / \mathrm{h}$ & $\begin{array}{l}\text { Danos devastadores: casas bem construídas } \\
\text { são completamente destruídas, carros são } \\
\text { arremessados, grandes objetos tornam-se } \\
\text { projéteis. }\end{array}$ \\
\hline EF5 INCRÍVEL & Mais de $322 \mathrm{~km} / \mathrm{h}$ & $\begin{array}{l}\text { Danos incríveis: casas são arremessadas a } \\
\text { certa distância e completamente destruídas, } \\
\text { projéteis do tamanho de carros voam mais de } \\
100 m \text { árvores são aniquiladas. }\end{array}$ \\
\hline
\end{tabular}

3.3. Caracterização do tornado ocorrido em Marechal Cândido Rondon e Quatro Pontes

De acordo com relatos de uma moradora local, no dia 19 de novembro de 2015 o "céu escureceu e uma nuvem estranha com fortes ventos começou a levantar tudo". As notícias do ocorrido demonstram o mesmo: "Um tornado deixou rastro de detruição em Marechal C. Rondon com rumo a Quatro Pontes" (JORNAL O PRESENTE, 2015), "os vendavais se tratam de um tornado $F 1$, com ventos entre 115 e $125 \mathrm{~km}$ por hora", segundo o Simepar (2015) e o Instituto Nacional de Meteorologia (INMET, 2015) "confirmou que um tornado atingiu a cidade de Marechal Cândido Rondon, no oeste do Paraná".

Em análise baseada em campo verificou-se que caminho de destruição foi de aproximadamente $16 \mathrm{~km}$ em um período de aproximadamente 15 minutos, logo calculou-se que a média de deslocamento do centro do tornado no chão foi de cerca de $64,08 \mathrm{~km} /$ hora de noroeste para sudeste, com diâmetro 


\section{CARACTERIZAÇÃO DO TORNADO OCORRIDO EM MARECHAL CÂNDIDO RONDON E QUATRO PONTES EM NOVEMBRO DE 2015}

máximo de circulação de 750 metros variando este do início ao término.

Nas palavras da Meteorologista, Sheila Radmann (SIMEPAR 2015): “O escoamento atmosférico nesta tarde sobre o Estado do Paraná contribuiu para a formação de uma célula tornádica que atingiu a região do município de Marechal Cândido Rondon e gerou danos na cidade" e ainda de acordo com ela:

Tecnicamente a circulação estava favorável para condições meteorológicas severas, a somatória de eventos pode ser compreendida por queda profunda na pressão atmosférica no interior do continente, choque térmico em torno de 2 $\mathrm{km}$ de altitude e convergência do fluxo de advecção fria de sul com os ventos quentes e úmidos dos Jatos de Baixos Níveis de noroeste, cavados no escoamento médio de oeste e jato subtropical escoando muito rápido sobre a região. Todas as condições potencializaram a convecção e o cisalhamento. (Sheila Radmann apud Simepar, 2015).
Segundo o CPTEC/INPE (2015), na análise da carta sinótica de superfície (Figura 5) das 12:00 horas do dia 19/11, observa-se um sistema de baixa pressão, cuja frente fria associada se aproxima do litoral norte de SC, com centro de $996 \mathrm{hPa}$ localizado em torno de $40^{\circ} \mathrm{S} / 48^{\circ} \mathrm{W}$. Nota-se também outro sistema de baixa pressão, em estágio de oclusão, com valor de $980 \mathrm{hPa}$ centrado em $60^{\circ} \mathrm{S} / 40^{\circ} \mathrm{W}$. Observa-se um sistema frontal sobre o Pacífico Sul, associado a uma baixa pressão relativa de $984 \mathrm{hPa}$, centrada em $61^{\circ} \mathrm{S} / 80^{\circ} \mathrm{W}$. A Alta Subtropical do Atlântico Sul (ASAS) encontra-se localizada em torno de $40^{\circ} \mathrm{S} / 18^{\circ} \mathrm{W}$ com valor de 1032 hPa. A Alta Subtropical do Pacífico Sul (ASPS), com valor de $1032 \mathrm{hPa}$, está localizada em torno de $38^{\circ} \mathrm{S} / 100^{\circ} \mathrm{W}$. A Zona de Convergência Intertropical (ZCIT) oscila entre $05^{\circ} \mathrm{N}$ e $11^{\circ} \mathrm{N}$ no Oceano Pacífico e entre $05^{\circ} \mathrm{N}$ e $11^{\circ} \mathrm{N}$ no Oceano Atlântico. Nesse patamar, observa-se que a região oeste do Paraná está sobre atuação dessa frente fria e que a instabilidade é alta, propiciando ao desenvolvimento rápido de nuvens.

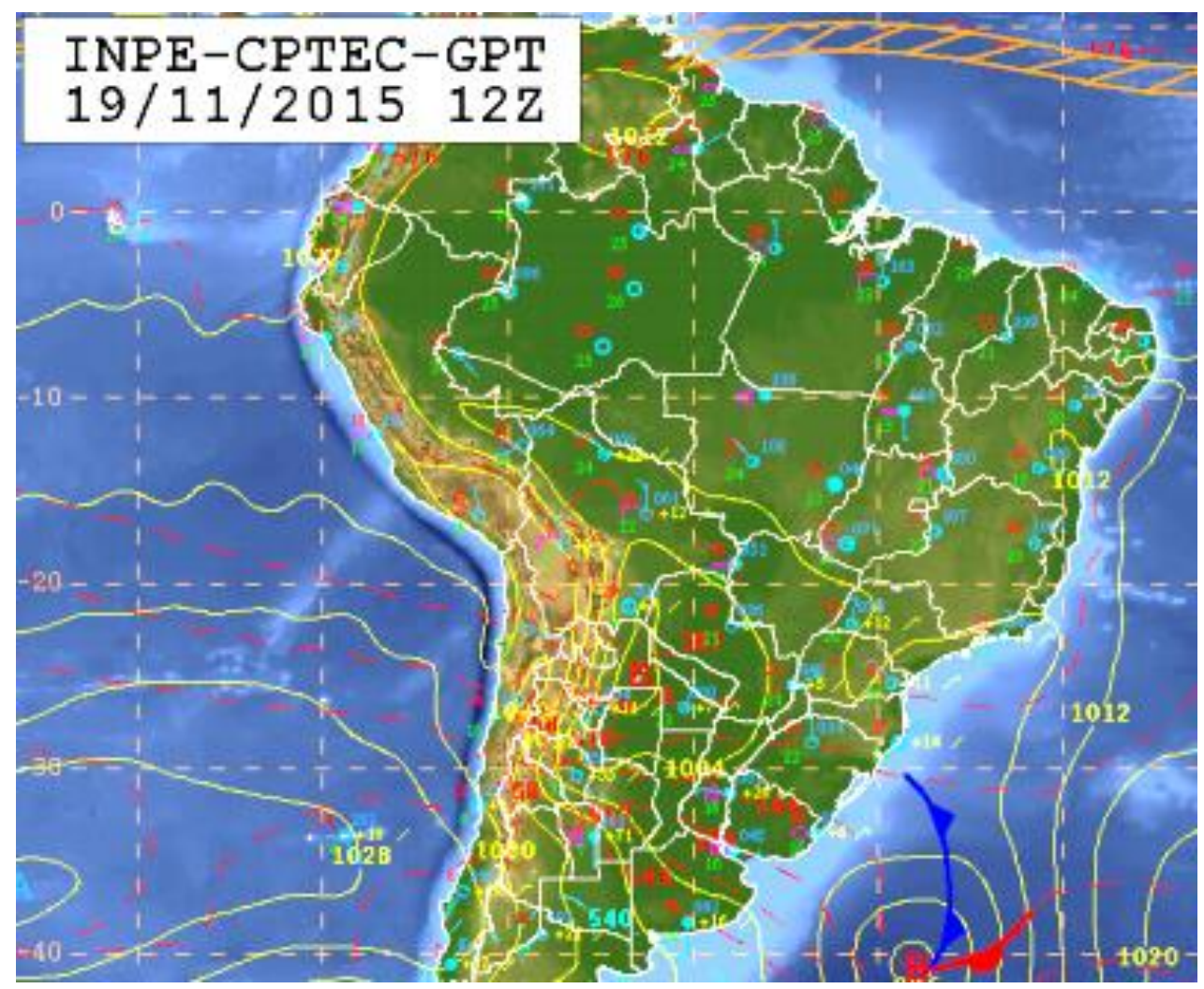

Figura 5 - Análise da carta sinótica do dia 19 de novembro as 12:00 horas. Fonte: INPE/CPTEC (2015). 


\section{CARACTERIZAÇÃO DO TORNADO OCORRIDO EM MARECHAL CÂNDIDO RONDON E QUATRO PONTES EM NOVEMBRO DE 2015}

A área de instabilidade se formou rapidamente sobre o extremo oeste do Paraguai, caracterizando como uma supercélula explosiva (Figura 6), de rápido desenvolvimento, capaz de gerar vendavais e tornados e que percorreu a direção de noroeste para sudeste, em direção ao Brasil, atingindo Marechal Cândido Rondon e Quatro Pontes. A sequência e o crescimento da nuvem geradora do tornado pode ser vislumbrado nos recortes da imagem GOES 13 infravermelho e vapor (INPE, 2015) com maior destaque para o local de ocorrência. O horário aproximado em que o tornado inicia o "toque no chão "ocorreu as 16:05 horas. Na verdade o tornado não tocou o chão em todo o campo verificou-se que ele tocou as estruturas mais altas não o chão. 0 horário condiz com o maior predomínio das ocorrências de tornados no EUA como descrito por NOAA (2016) onde existe um maior acúmulo de calor latente.

Após analisar o sistema comparando com o ocorrido em Marechal C. Rondon percebe-se que $O$ mesmo apresentou características do sistema convectivo caótico como demonstrado a seguir na figura $06 . \mathrm{Na}$ análise da sua evolução (Animação não disponível no presente artigo) com auxílio de imagens de satélite GOES 13 canal vapor e infravermelho foi possível verificar que o sistema surgiu de forma explosiva na escala temporal e iniciou-se de forma isolada. Nesse quesito, à medida que a chuva desce da média troposfera, surge um resfriamento evaporativo do ar abaixo das bases das nuvens, gerando correntes descendentes e criando um sistema de alta pressão, com alguns milibares de intensidade. Porém, o ar quente próximo é mais leve e portanto é forçado a elevar-se a troposfera média, surgindo assim um influxo interno, para repor esse vazio deixado pela elevação. Isso faz essa grande tempestade desenvolver-se a ponto de formar abundância de chuva e eventualmente, grandes quantidades e diferentes tamanhos de granizo, devido à elevação a altas camadas da atmosfera, que são muito frias. No caso específico do ocorrido na cidade não houve menção de queda de granizo apenas uma leve garoa antes de sua passagem e posterior precipitação após sua passagem.

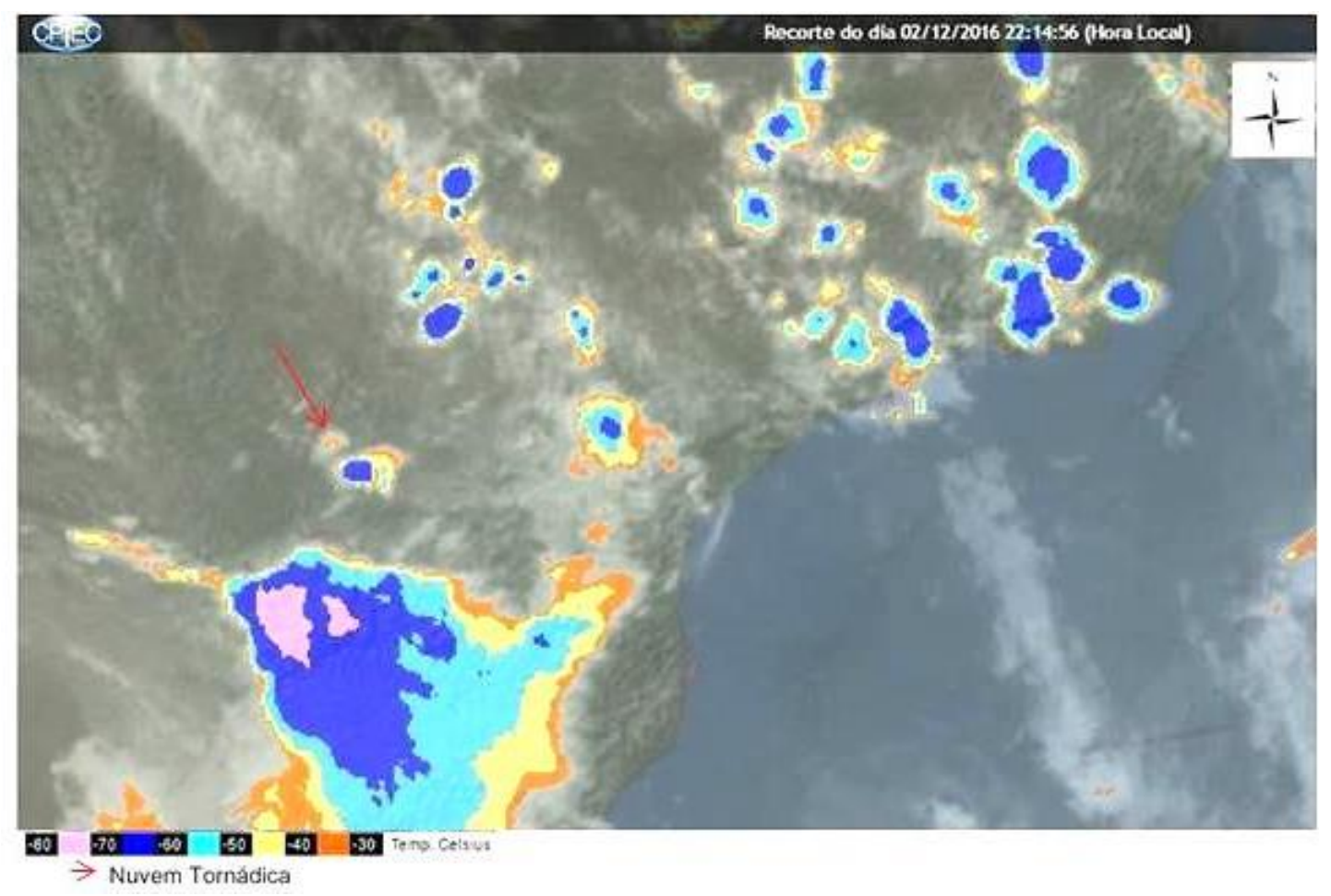

Figura 6 - Imagem radar Goes infravermelho termal. Fonte: (INPE/CPTEC 2015). 


\section{CARACTERIZAÇÃO DO TORNADO OCORRIDO EM MARECHAL CÂNDIDO RONDON E QUATRO PONTES EM NOVEMBRO DE 2015}

A evolução da nuvem foi intensa e rápida. A temperatura apresentada da nuvem estava entre $-40 \circ \mathrm{C}$ e $-50 \circ \mathrm{C}$ como demonstrado na figura 6 . Observa-se também a presença de um gancho (figura 7 echo), que possivelmente seja a cauda 16:15 horas local. Não houve queda de granizo no dia, possivelmente isto se deve ao não total crescimento vertical da nuvem.

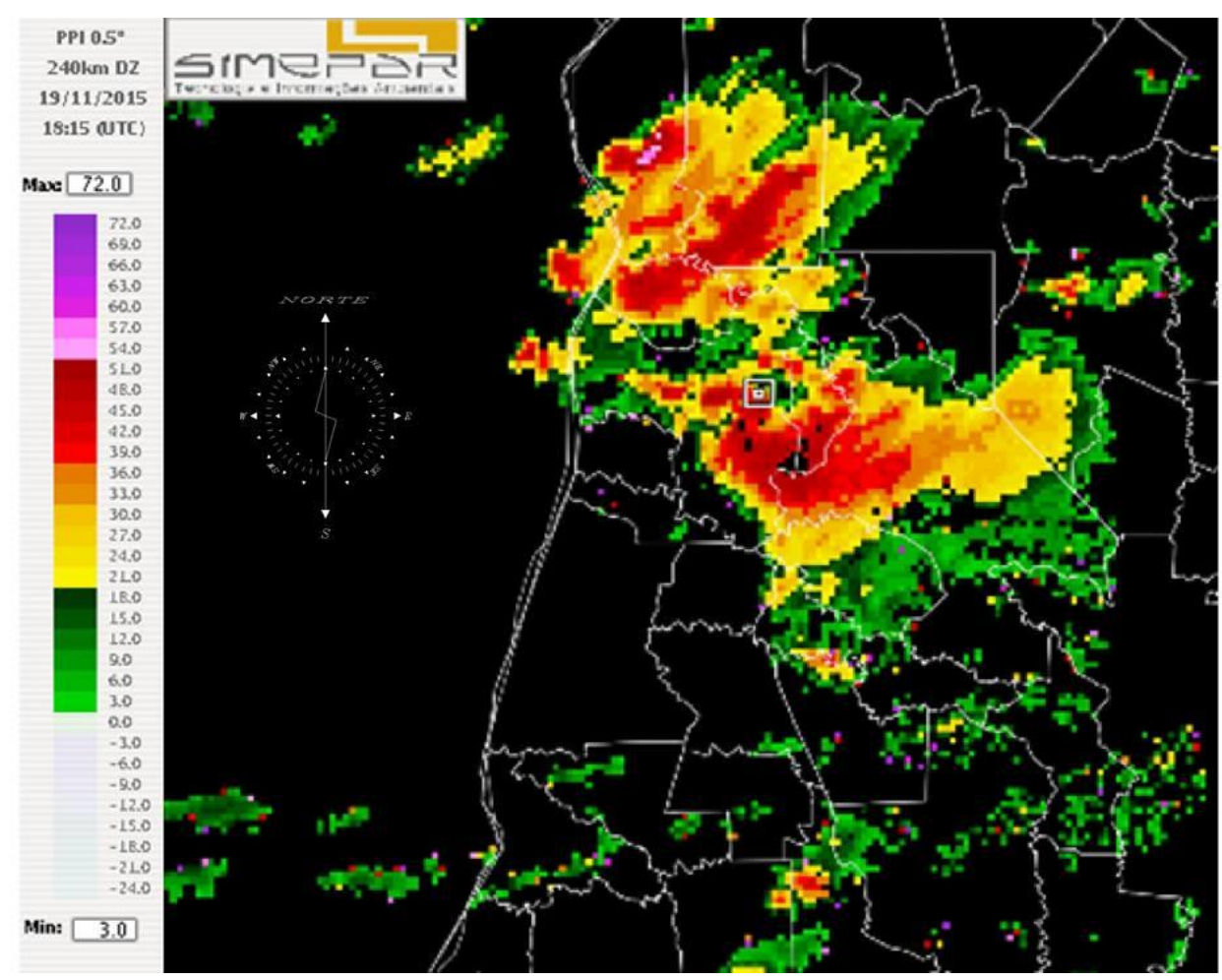

Figura 7 - Imagem de radar fornecida pelo Simepar (Sistema Meteorológico do Paraná) Flecha mostrando o eco gancho e desenvolvimento da super-célula. Fonte: Simepar (2016).

Um item não discutido e que pode estar associado ao evento, no entanto são necessárias mais informações a respeito, se refere a temperatura do solo, como ilhas de calor, por exemplo. Conforme Carvalho (G1, 2016), meteorologista do Inmet ele afirma que a combinação de uma temperatura muito alta no solo e uma alta cobertura de nuvens que impedem a troca deste ar em conjunto com a chegada de uma frente fria, podem criar correntes de vento que podem vir a tomar a forma de um funil. No quadro a seguir foram tabuladas algumas informações disponíveis pela Estação Experimental Prof. Dr. Antonio Carlos dos Santos Pessoa, situada no município de Marechal Cândido Rondon, Linha Guará. Estação esta realizada em convênio entre o Instituto Nacional de Meteorologia (INMET) e
Universidade Estadual do Oeste do Paraná (UNIOESTE). A mesma dista aproximadamente $5 \mathrm{Km}$ de algumas áreas atingidas pelo tornado.

A seguir estão descritas algumas informações meteorológicas (Quadro 2) a respeito do dia da atividade tornádica. Nota-se que houve uma diminuição da temperatura de ponto de orvalho pressão atmosférica e diminuição da radiação. A precipitação foi nula a mesma ocorrendo posteriormente próximo as 20:00. A rajada do vento registrada foi de 54 $\mathrm{km} / \mathrm{h}$ as $16: 00$ e caiu para $26 \mathrm{~km} / \mathrm{h}$ as $17: 00$, a cobertura de nuvens também foi alta como pode ser verificado nos dados da radiação vindo a cair (cobertura de nuvens) posteriormente. A direção do vento mudou repentinamente das 16:00 para as 17:00 soprando de NNE - SSW para ESSE - WNW. A 


\section{CARACTERIZAÇÃO DO TORNADO OCORRIDO EM MARECHAL CÂNDIDO RONDON E QUATRO PONTES EM NOVEMBRO DE 2015}

direção obtida pela estação não corresponde a direção percorrida pelo tornado verificada na presente pesquisa. Provavelmente a forte rajada registrada de direção NNE - SSW esteja relacionada a alimentação do flanco ou ao vento cortante, ou ao vento pré-frente. Para existência do tornado haveria a necessidade de duas direções de ventos que em determinado ângulo possibilitassem a formação de um vórtice. Assim analisando a figura do percurso em concomitância com a rajada registrada. Acredita-se que o deslocamento do tornado tenha a direção de ângulo aproximado de 286응 sofrendo influência das rajadas cortantes de 19 formando então um ângulo de 93 graus de encontro de ventos que proporcionariam a criação do vórtice.

Tabela 2 - Dados meteorológicos da estação mais próxima, no município de Marechal Cândido Rondon. Fonte: UNIOESTE, INMET (2017).

\begin{tabular}{|c|c|c|c|c|c|c|c|}
\hline DATA & 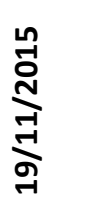 & م્ & 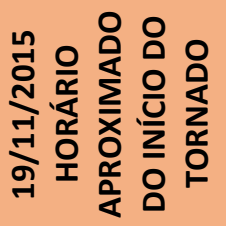 & م્ & 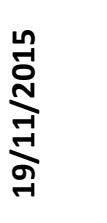 & 帒 & 帒 \\
\hline HORA & $14: 00$ & $15: 00$ & $16: 00$ & $17: 00$ & $18: 00$ & 19:00 & 20:00 \\
\hline $\begin{array}{c}\text { TEMPERATURA } \\
\text { MÉDIA ( C) }\end{array}$ & 27 & 26,4 & 24,6 & 24,8 & 25,3 & 24,4 & 20,5 \\
\hline $\begin{array}{c}\text { UMIDADE } \\
\text { RELATIVA (\%) }\end{array}$ & 77 & 74 & 81 & 81 & 82 & 87 & 87 \\
\hline $\begin{array}{c}\text { TEMPERATURA } \\
\text { DO PONTO DE } \\
\text { ORVALHO }\end{array}$ & 22,9 & 23,3 & 22,2 & 21,9 & 22,5 & 23 & 19,7 \\
\hline $\begin{array}{c}\text { PRESSÃO } \\
\text { (HPA) }\end{array}$ & 957,3 & 955,5 & 954,2 & 954,1 & 953,9 & 953,8 & 954,7 \\
\hline $\begin{array}{c}\text { VELOCIDADE } \\
\text { DO VENTO } \\
\text { (M/S) }\end{array}$ & 5,2 & 3,4 & 1,3 & 4,8 & 2,5 & 0 & 10,2 \\
\hline $\begin{array}{c}\text { DIREÇÃO DO } \\
\text { VENTO } \\
\text { (GRAUS) } \\
\end{array}$ & 38 & 62 & 19 & 100 & 93 & 225 & 186 \\
\hline RAJADA & 8,7 & 8,3 & 15,1 & 7,3 & 6,5 & 5,5 & 26 \\
\hline $\begin{array}{c}\text { RADIAÇÃO } \\
\text { (KJ/M2) }\end{array}$ & 2571 & 903,2 & 546,8 & 1254 & 758,2 & 54,85 & 2 \\
\hline CHUVA (MM) & 0 & 0,2 & 3 & 0 & 0 & 0,4 & 11,4 \\
\hline
\end{tabular}

Através de imagens e atividades campo em conjunto com questionários e entrevistas, foi possível definir que o tornado ocorrido na cidade foi do tipo Múltiplo Vórtice. Eles são responsáveis na maioria das vezes, por distintas destruições onde danos de diferentes intensidades podem coniver lado a lado (NOAA, 2015). No caso específico de Marechal, foi possível contabilizar até cinco vórtices tocando o solo ao mesmo tempo (Figura 08).
Pode-se ainda identificar alguns arcos de destruição onde o nível de estrago chegou na categoria de um EF 2 na escala melhorada Fujita o que corresponderia a nível de destruição 3 e 4 definidos pela pesquisa sendo estes os que mais apresentaram danos. O nível de destruição 1 e 2 equivaleriam ao EF1 e o nível 0 ao EFO (Figura 9). A seguir apenas uma parte do percurso foi apresentada. Há de se destacar que o comportamento do tornado não seguiu do princípio ao fim o mesmo padrão, 


\section{CARACTERIZAÇÃO DO TORNADO OCORRIDO EM MARECHAL CÂNDIDO RONDON E QUATRO PONTES EM NOVEMBRO DE 2015}

pois os níveis de destruição foram aleatórios também variou do início ao término do em solo e o tamanho do caminho da destruição fenômeno.
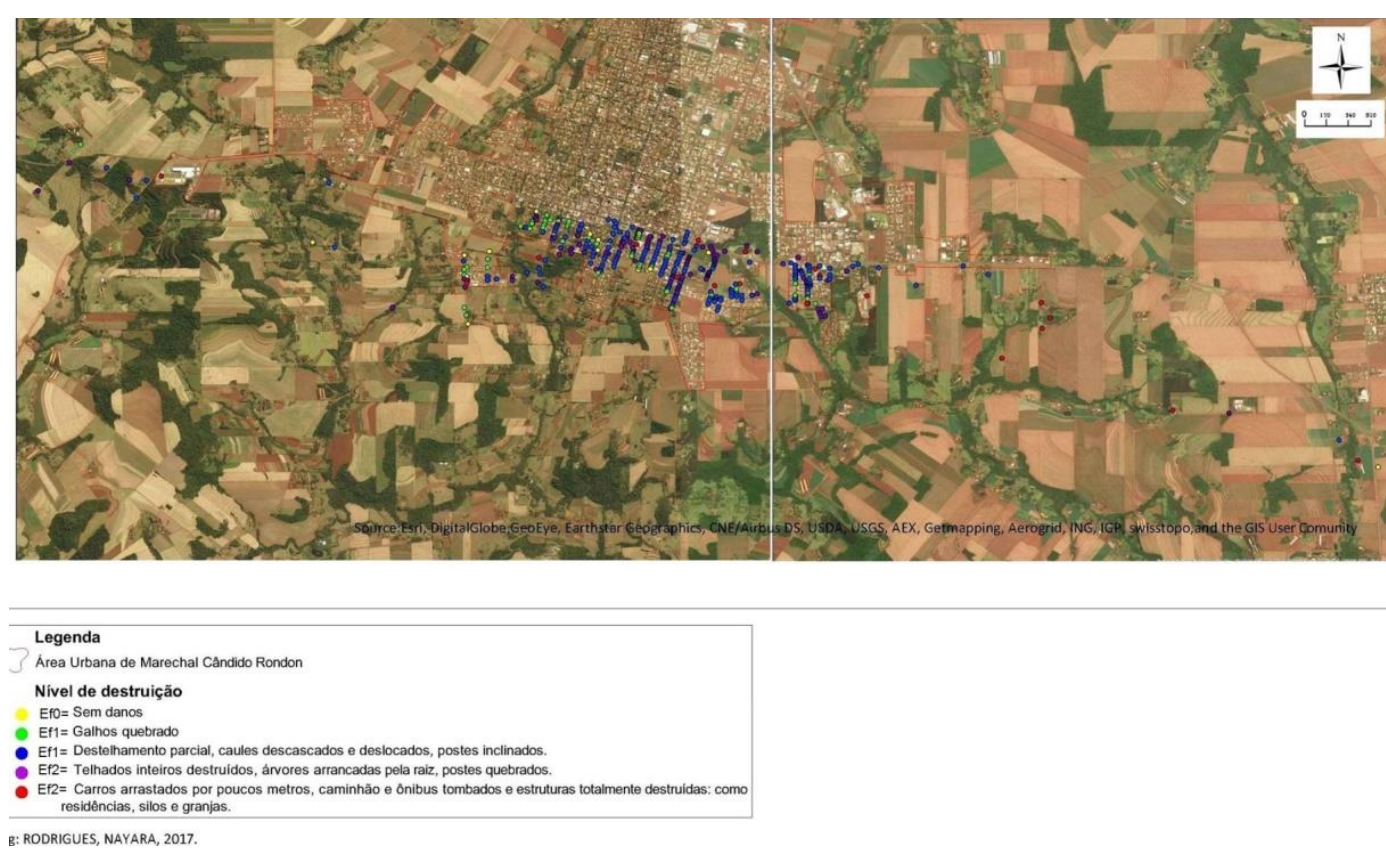

Figura 8 - Níveis de destruição em parte do percurso do tornado em Marechal Cândido Rondon. Fonte: RODRIGUES, N. A.; HORNES; K. L. (2016).

\section{É interessante mencionar que} pouquíssimas pessoas (apenas 2) relataram ter visto mais funis os demais sempre relataram apenas um e a maioria não conseguiam entender direito o que estava ocorrendo. Após a visualização de vídeos do evento foi possível constatar que o tornado mudou a dinâmica de múltiplos vórtices e acabou assumindo dois grandes vórtices (Figura 10) e posteriormente um único. Mas há de se destacar que conforme a distância do fenômeno o mesmo tende a ser visualizado com um único vórtice. Pois é na parte inferior que se manifestam os sub vórtices a aproximadamente 20 metros de altura.

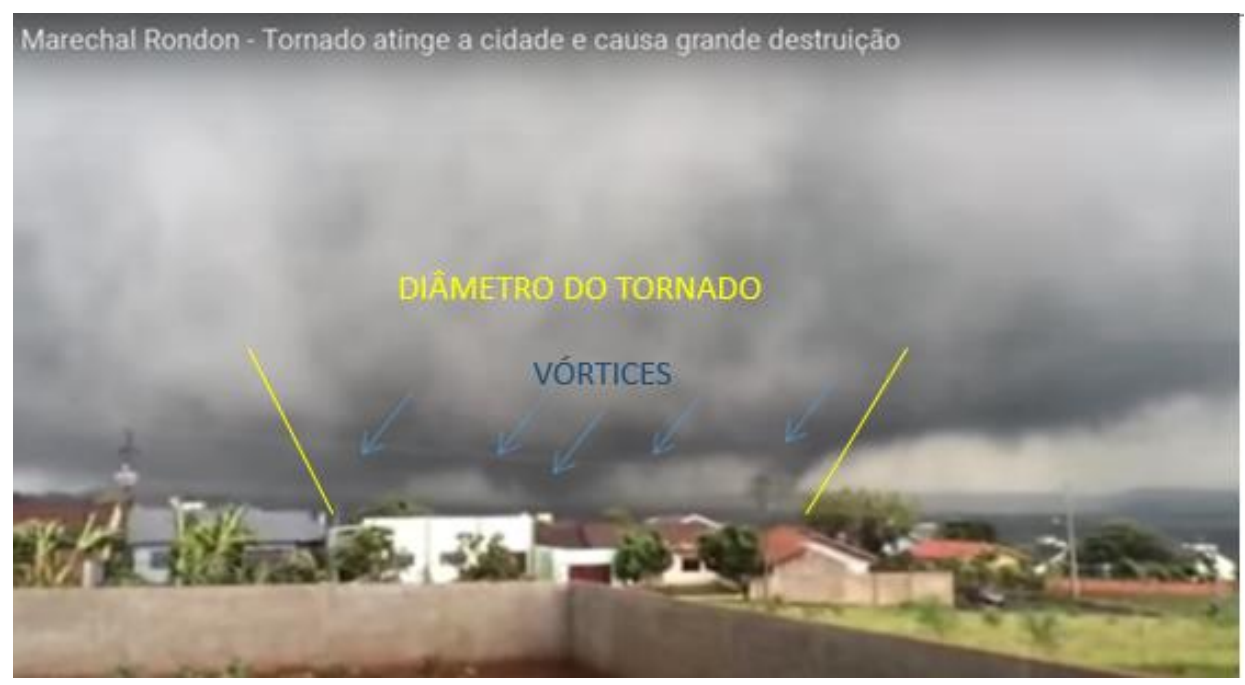

Figura 9 - Tornado de múltiplo vórtices atingido as proximidades da Vila Gaúcha (sobre o perímetro urbano de Marechal C. Rondon). Fonte: Regis A. Guerreiro, (Adaptado de Youtube, 2016). 


\section{CARACTERIZAÇÃO DO TORNADO OCORRIDO EM MARECHAL CÂNDIDO RONDON E QUATRO PONTES EM NOVEMBRO DE 2015}
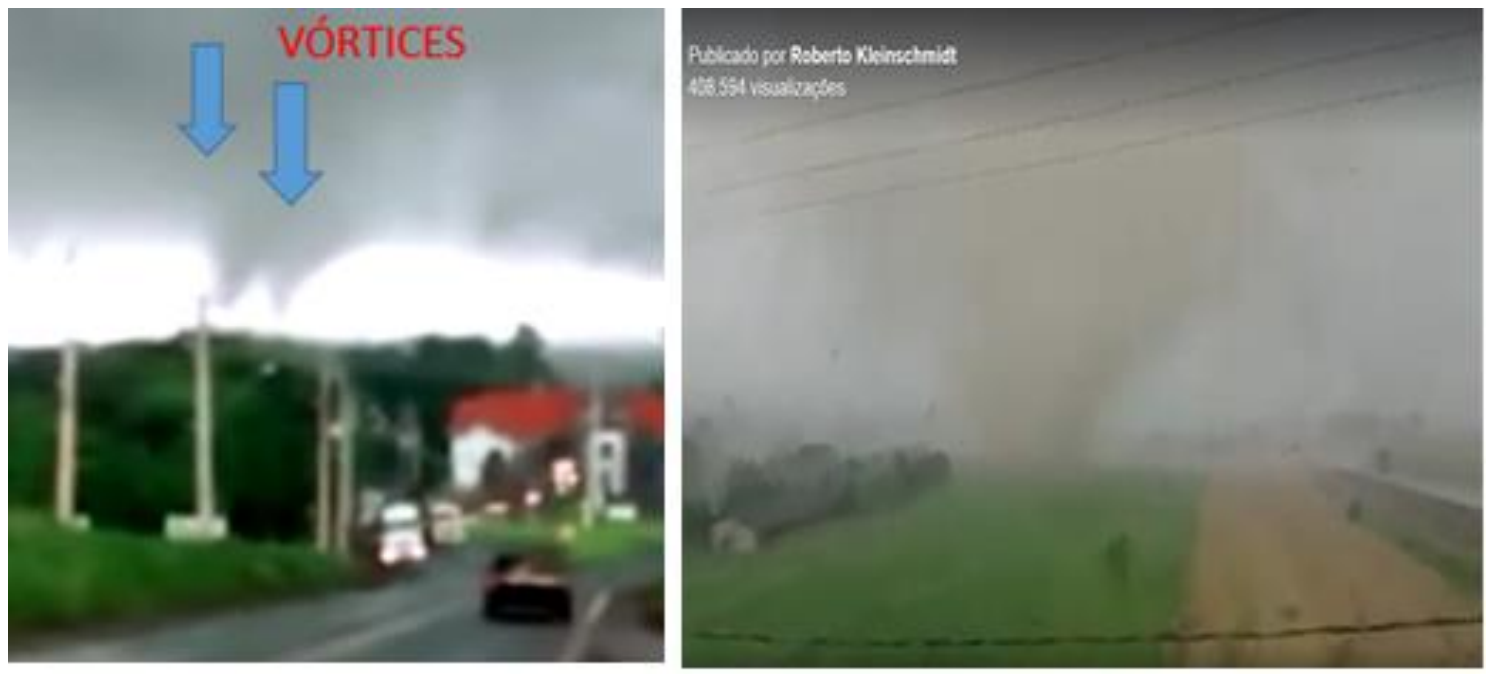

Figura 10 - Tornado múltiplos vórtices próximo do portal da cidade de Marechal Candido Rondon (esquerda) e do portal de Quatro Pontes (direita). Fonte: imagens frame vídeos YouTube por Gerson

Cardoso (esquerda, momento com 2 vórtices) e Roberto Kleinschmidt (direita, com 1 vórtice).

O esquema lateral da super-célula tornádica descrito na figura 4 exemplifica o ocorrido na cidade como pode ser vislumbrado na Figura 11 que apresenta a visão lateral da super-célula sobre Marechal Cândido Rondon. Com o diferencial de que a direção percorrida foi de NW para SE.
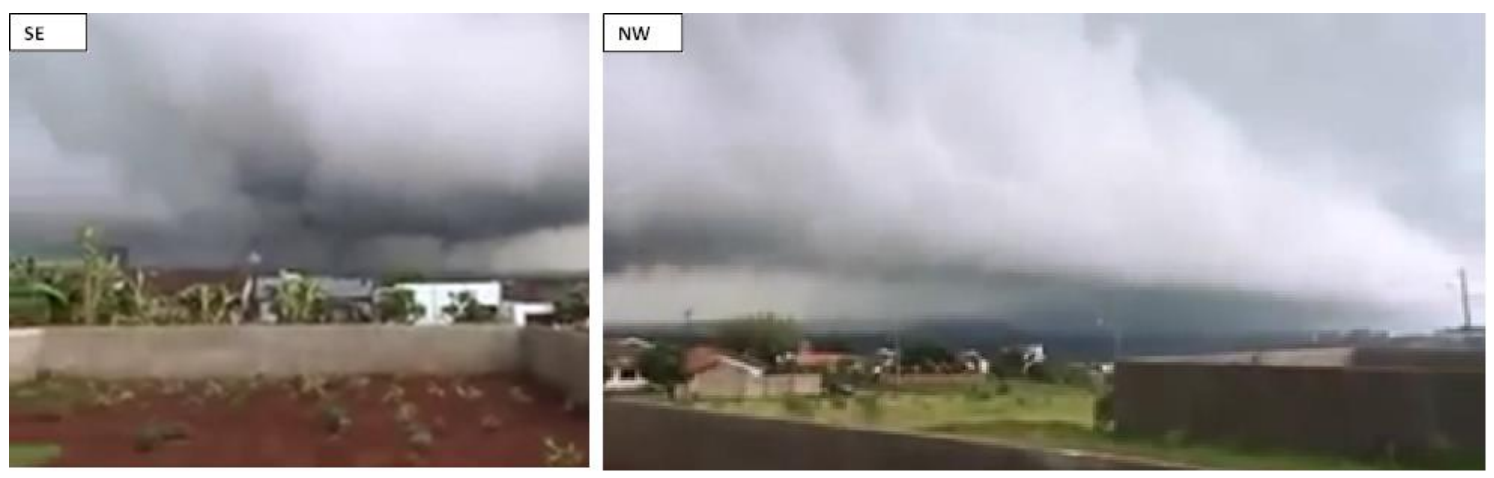

Figura 11 - Super-célula tornádica de Marechal Cândido Rondon. Fonte: Adaptado de Regis A. Guerreiro (2016).

\subsection{DANOS SOCIOECONÔMICOS}

Em relação aos danos econômicos, o município estimou que chegaram na casa de R\$ 91 milhões, o que permitiu a decretação de estado de emergência pelo prefeito Moacir Froehlich (PREFEITURA MUNICIPAL DE MARECHAL CÂNDIDO RONDON, 2015). O número de feridos foi 23 , felizmente nenhuma morte direta. A partir da avaliação dos danos a categoria dada ao Tornado ocorrido em MCR foi a de EF2, discordando da publicada pelo Simepar (BLOGSPOT, 2015). A definição desta categoria se baseou na classificação da escala Fujita melhorada que leva em consideração o nível de destruição do fenômeno. $\mathrm{Na}$ classificação Fujita um EF2, possui as seguintes características de destruição e de velocidade do vento acima de $180 \mathrm{~km} /$ hora. A seguir pode-se verificar que a força do tornado arrancou árvores (Figura 12A) tombou caminhões (Figura 12B) e ônibus. Além de danificar diversos postes e arrancar totalmente ou parcialmente o telhado de muitas residências, silos, indústrias e barracões (Figuras, 13A, 13B, 14A e 14B). 


\section{CARACTERIZAÇÃO DO TORNADO OCORRIDO EM MARECHAL CÂNDIDO RONDON E QUATRO PONTES EM NOVEMBRO DE 2015}

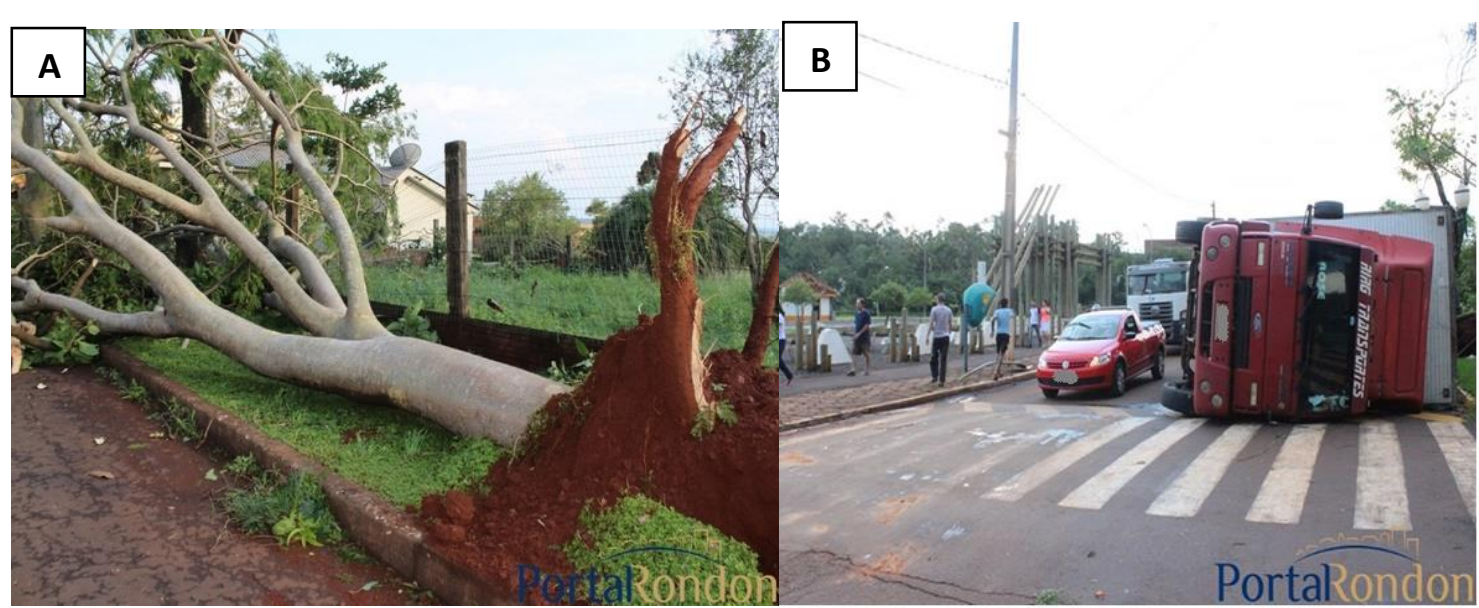

Figura 12A - Árvores arrancadas pela raiz Fonte: Portal Rondon. Figura 12B - Caminhão tombado em frente ao lago Municipal configurando EF2. Fonte: Portal Rondon.

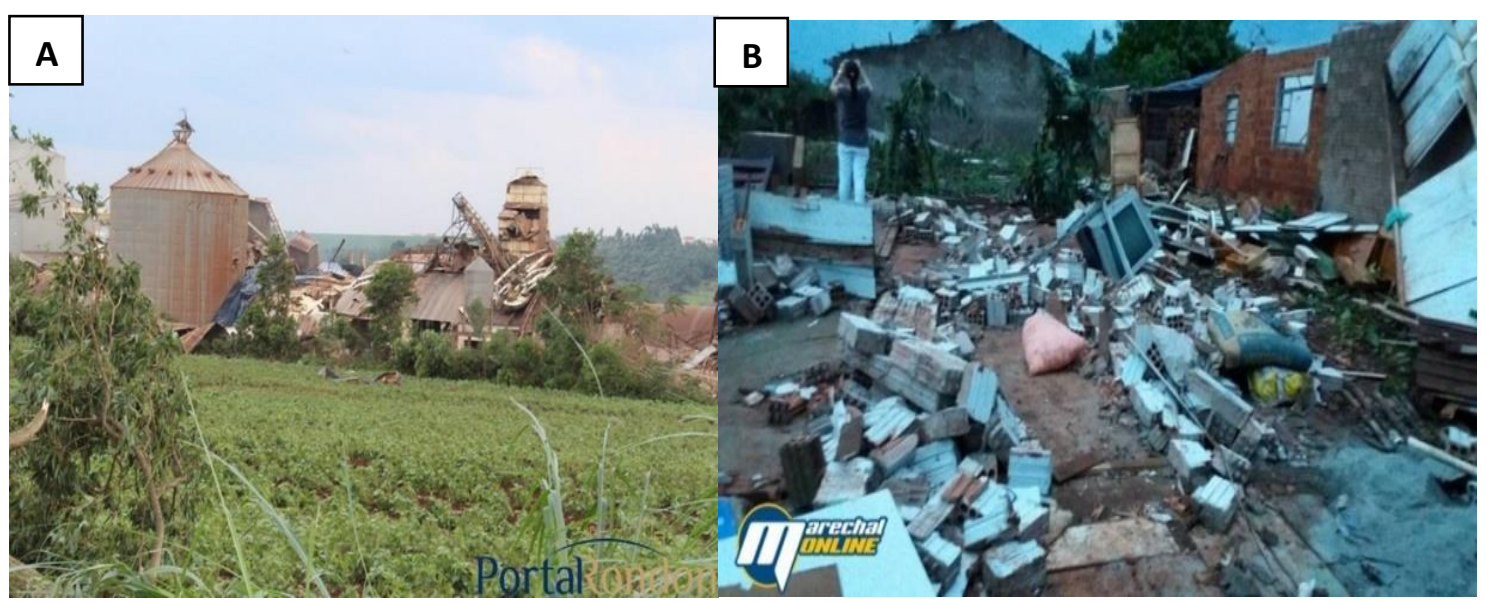

Figura 13A - Destruição no complexo industrial. Fonte: Portal Rondon. Figura 13B - Casas destruídas no perímetro urbano Fonte: Marechal Online.

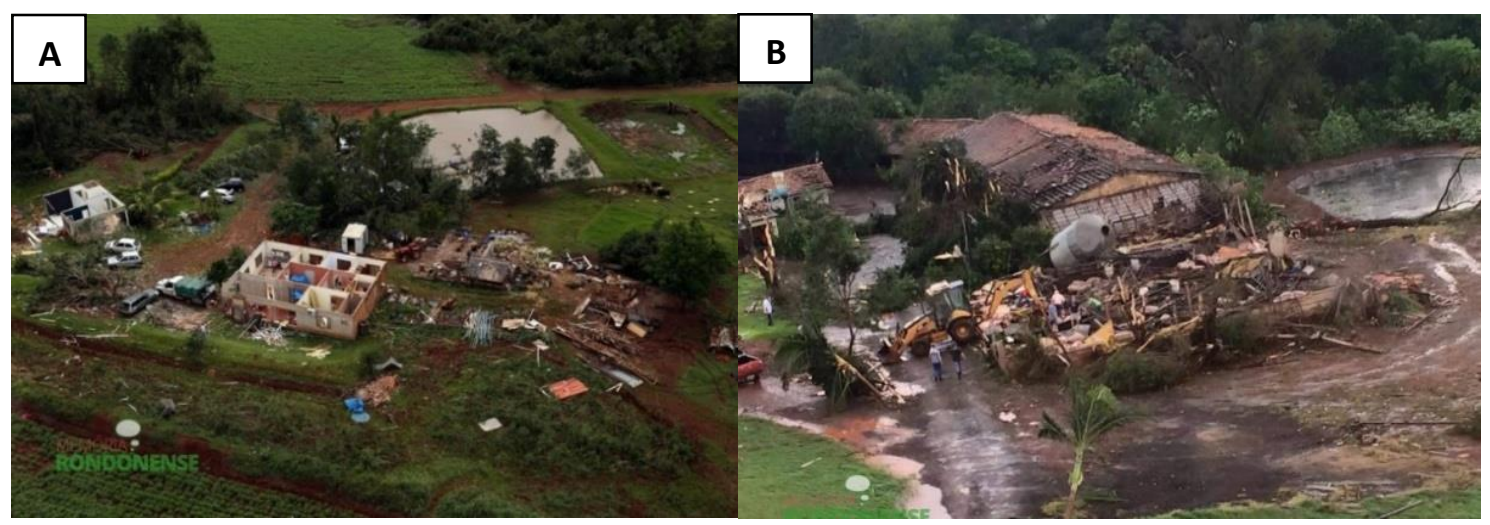

Figura 14A - Casas destruídas no interior do município Marechal C. R. caracterizando força EF2. Fonte: memoriarondonense. Figura 14B - chiqueirões destruídos no interior do município de Quatro Pontes. Fonte: memoriarondonense.

\section{CONSIDERAÇÕES FINAIS}

Como concordante com a descrição da literatura (INPE, 2015) a respeito das estações preferencias da atuação dos tornados, o fato ocorrido em Marechal (19 de novembro) reafirmou a preferência pelos equinócios de privamera. O mesmo surgiu a frente de um complexo convectivo de meso escala 


\section{CARACTERIZAÇÃO DO TORNADO OCORRIDO EM MARECHAL CÂNDIDO RONDON E QUATRO PONTES EM NOVEMBRO DE 2015}

concordando com os padrões caóticos de instabilidade descrito por Barry e Chorley (2013) que surgem de choque de massas. O deslocamento do tornado foi movido por ventos de nordeste para sudeste. No mesmo dia ocorreram atividades tornádicas em outros locais como em Irunã - Paraguay (VANGUARDIA, 2015) e em outros estados do Brasil, como na cidade de Chapecó e Treze Tilias em Santa Catarina (G1, 2015).

O meteorologista do Inmet, Hamilton Carvalho $(G 1,2015)$ afirma que apesar de a estação do Paraná não ter captado o tornado em Marechal Cândido Rondon, foi possível identificar o fenômeno pelas imagens, pela formação de nuvens favoráveis e pelo registro de ventos. Pode-se verificar na presente pesquisa esta assinatura ou seja o eco-gancho nas imagens. Dessa forma conclui-se que o fenômeno possuí uma marca de identificação mas devido a sua rapidez de crescimento e desenvolvimento fica difícil a sua detecção.

A pesquisa confirmou que o tornado ocorrido foi do tipo múltiplo vórtice. Esta afirmação pode ser realizada a partir da categorização dos níveis de estragos onde os arcos de destruição puderam ser vislumbrados e por filmagens que permitiram verificar a atuação dos subvórtices em solo. O tornado ocorrido em Marechal iniciou em uma lavoura de soja mas não tocou o chão propriamente dito, pois não encontrou-se danos nas plantações visitadas o mesmo atingiu as estruturas mais altas como telhados árvores e postes. A altitude equivale. A variação topográfica do caminho de destruição foi de 350 metros a 450 metros.

Após a realização da pesquisa sugerese que ocorra a implantação de sistemas de monitoramento e a realização de mais pesquisas que comparem as informações coletadas para que se possam realizar estratégias mais refinadas de alertas para possíveis tempestades severas. A partir da verificação da intensidade deste fenômeno e do desconhecimento da população perante a sua atuação sugere-se que um dos primeiros passos é assumir que o fenômeno existe e que - Paraná é palco deste, posteriormente sensibilizar a população e o poder público a respeito das suas causas e consequências, e assim propor melhorias de estruturação de residências e construção de abrigos para que vidas possam ser salvas. Além de orientar a defesa civil de cada município de como agir em momentos como este. A realização de alertas auxiliaria grandemente na minimização de impactos.Espera-se que os órgãos responsáveis pela interpretação principalmente dos radares Doppler do Estado, dediquem uma equipe especializada e realizem atividades em parceria com universidades, escolas, defesa civil, bombeiros para divulgar mais os alertas e as ações que devem ser tomadas em momentos de tempestades severas.

\section{REFERÊNCIAS}

ALCÁNTARA-AYALA, I. Geomorphology, Natural Hazards, Vulnerability and Prevention of Natural Disasters in Developing Countries. Geomorphology, v. 47, n. 2-4, p. 107-124, 2002.

ATLAS DE DESASTRES NATURAIS. Volume Brasil. 2012. Disponível em: < http://150.162.127.14:8080/atlas/Brasil\%20Re v\%202.pdf> acesso em: 10 fev. de 2016.

BARRY,R.G.;CHORLEY,R.J. Atmosfera Tempo e Clima. 9o edição. Porto Alegre. Bookman.2013.

BERTONI, B. G. L.; ANDRÉ I. R.N.; AZEVEDO T.S.D Análise da ocorrência do Tornado no Município de Indaiatuba (2005) e a correlação entre o relevo e a topografia da região. Sociedade brasileira de Meteorologia, 2013. Disponível em < http://www.sbmet.org.br/cbmet2010/artigos/4 81_86971.pdf> Acesso em: 10 fev. 2016.

BLOGSPOT. Tornado F2 passa por Marechal C. Rondon. Disponível em: < http://viveremfozdoiguacu.blogspot.com.br/20 15/11/tempo-e-temperatura-em-foz-do- 


\section{CARACTERIZAÇÃO DO TORNADO OCORRIDO EM MARECHAL CÂNDIDO RONDON E QUATRO PONTES EM NOVEMBRO DE 2015}

iguacu-tornado-passa-a-157-km-de-foz.html> Acesso em: 19 jun. 2016.

CANDIDO, D. H. Na Rota dos Tornados. Disponível em: $<$ http://www.unicamp.br/unicamp/sites/defaul t/files/jornal/paginas/ju539pag03.pdf.> Acesso em: Acesso em: 11 mar. 2016.

CANDIDO, D. H. Tornados e trombas-d 'água no Brasil: modelo de risco e proposta de escala de avaliação de danos. Universidade Estadual de Campinas, Instituto de Geociências; Campinas, SP.: [s.n.], 2012.

CLIMATEMPO. Diferença entre tornado e micro explosão. Disponível em: <http://www.climatempo.com.br/noticia/2016 /05/16/qual-a-diferenca-entre-tornadodownburst-e-micro-explosao--2441> Acesso em: 18 dez. 2015.

CEPED/UFSC. Radar Meteorológico. Disponível em: <http://www.ceped.ufsc.br/entendacomo-o-maior-centro-meteorologico-dos-euareune-informacoes-para-previsao-do-tempo/ > Acesso em: 19 jun. 2016.

CPTEC/INPE. Imagens de satélite Goes. Disponível em: <http://enos.cptec.inpe.br/> Acesso em: 17 dez 2015.

CPTEC/INPE. Arquivo digital/satélite. GOES 13. Disponível em: < http://satelite.cptec.inpe.br/acervo/goes.form ulario.logic> acesso em: 19 jun. 2016.

CHRISTOPHERSON, Robert W. Geossistemas Uma Introdução à Geografi a Física. 7ạ ed. Tradução: Francisco Eliseu Aquino. Porto Alegre: Bookman, 2012. . Acesso: 12 de dez. de 2014.

DAMMOUS. Figura 1. Disponível em: <http://www.dammous.com/tempo/to_dsnv.a sp>Acesso em:13 dez. 2015.

DOSWELL, C.A.; BRUGESS, D. W. Tornadoes and Tornadic Storms: A Review of Conceptual
Models. In: $\mathrm{CHURCH}, \mathrm{C}$. et al. (E.d.) The Tornado: its structure, dynamics, prediction, and hazards. Geophysical Monograf, (S.I.)n . 79, p. 161-172, 1993.

FUJITA, T. T. Tornadoes Around the World. Weatherwise, v. 26, p. 56-62, 1973.

FUJITA, T. T.: Proposed characterization of tornadoes and hurricanes by area and intensity. Satellite and Mesometeorology Research Project Report 91, Univ. of Chicago, 42 pp, 1971.

FUJITA, T. T.; FORBES, G. S.; UMENHOFER, T. A.: Close-up view of 20 March 1976 tornadoes: sinking cloud tops to suction vortices. Weatherwise, v. 29, p.116-131, 1976.

G1.Disponível em: <http://g1.globo.com/pr/oestesudoeste/noticia/2015/11/tornado-atingemarechal-candido-rondon-e-deixa-rastro-dedestruicao.html> Acesso em:17 dez.2015.

G1. INMET confirma tornado em Xapecó/SC. Disponível em: < http://g1.globo.com/sc/santacatarina/noticia/2015/11/inmet-confirmapassagem-de-tornado-em-chapeco-sc-houveferidos.html> Acesso em: 19 jun. 2016.

Gazeta do Povo. Disponível em: <http://www.gazetadopovo.com.br/vida-ecidadania/simepar-instala-segundo-radarmeteorologico-do-pr-em-cascavel8ww6yl1i4inuctrkeiblixp3i> Acesso em:17 dez. 2015.

GUERREIRO, R. A. Disponível em: $<$ https://www.youtube.com/watch?v=htpuzzO 8j9Y> Acesso em: 25 jan. 2016.

HUSHCKE, R.E. Glossary of Meteorology. Boston: American Meteorological Society, 1959. 585p.

RODRIGUES, N. A.; Caracterização da atuação do Tornado ocorrido em 19 
HORNES, K. L., BALICKI, M.

\section{CARACTERIZAÇÃO DO TORNADO OCORRIDO EM MARECHAL CÂNDIDO RONDON E QUATRO PONTES EM NOVEMBRO DE 2015}

de Novembro De 2015 Em Marechal Cândido Rondon e Quatro

Pontes - Pr 80 f. Monografia graduação. Curso de licenciatura em Geografia. Marechal Cândido Rondon 2017.

INMET.Tornado em Treze Tílias. Disponível em:

<http://g1.globo.com/sc/santacatarina/noticia/2015/11/alem-de-chapecoinmet-confirma-tambem-tornado-em-trezetilias-sc.html> Acesso: 19 jun. 2016.

INPE. Glossário. Disponível em: < http://www.cptec.inpe.br/glossario.shtml> acesso em: 10/dezembro/2015.

JORNAL DE SANTA CATARINA. Como funciona um radar meteorológico. Disponível em: <http://jornaldesantacatarina.clicrbs.com.br/sc /geral/noticia/2014/09/saiba-como-funciona-oradar-meteorologico-de-sc-4610074.html > Acesso em:11 Mar. 2016.

JORNAL O PRESENTE. Tornado em Marechal C. Rondon. Disponível em: < http://www.opresente.com.br/marechal/2015/ 11/tornado-atinge-marechal-candido-rondone-deixa-rastro-de-destruicao/2031290/> Acesso em: 19 jun. 2016.

KOBIYAMA, M. et al. Prevenção de desastres naturais: conceitos básicos. Curitiba: Organic Trading, 2006. 109 p.

MARCELINO, I. Análise do tornado ocorrido em Muitos Capões/RS no dia 29/08/2005. INPE (2007). Disponível em:

<http://www.metsul.com/_editor/filemanage r/files/2007a/inpe_muitos_capes.pdf> Acesso em: 19 jun. 2016.

MARCELINO, I. P. V. O.; FERREIRA, N. J.; CONFORTE, J. C. Análise do episódio do tornado ocorrido no dia 07/02/98 no município de Abdon Batista - SC. In: Simpósio Brasileiro de Sensoriamento Remoto, 11., 2003, Belo
Horizonte. Anais... São José dos Campos: INPE, 2003. p. 05-10. 1.

MARTINS, F. R; et al. Aproveitamento da Energia Eólica. Rev. Bras. Ensino Fís. vol.30 no.1 São Paulo 2008. Disponível em: $<$

http://www.scielo.br/scielo.php?script=sci_artt ext\&pid=S1806-11172008000100005\#nt01>

Acesso em: 19 jun. 2016.

Memoria Rondonense. Arquivo de fotos. Disponível em: < http://www.memoriarondonense.com.br/galer ia-single/tornado-em-19-de-novembro-de2015/41/?fb_comment_id=1080462778651709 _872181362877546> Acesso em: 27 nov. 2015.

NASCIMENTO E. D. L.; HELD H.; GOMES A. M. A Multiple-Vortex Tornado in Southeastern Brazil. Disponível em http://journals.ametsoc.org/doi/pdf/10.1175/ MWR-D-13-00319.1 Acessado em 11 de jul. de 2016.

NOAA. Historical Records and Trends. Disponível em <https://www.ncdc.noaa.gov/climateinformation/extreme-events/us-tornadoclimatology/trends>. Acesso em: 30 mar.2016.

NOAA. Multiple Vortex Tornado. Disponível em: <http://www.spc.noaa.gov/faq/tornado/altus.h tml> Acesso em: 12 mai. 2016.

NOAA. National Weather Service. Disponível em: <http://www.spc.noaa.gov/efscale/> Acesso em: 4 out. 2015.

NSSL . National Weather Service. Disponível em:

http://www.nssl.noaa.gov/education/svrwx101 /tornadoes/types> Acesso em: 4 out. 2015

OBSERVATÓRIO DAS CHUVAS. Disponível em: <http://www.brasil.gov.br/observatoriodaschu vas/monitoramento/radares.html > Acesso em: 19 jun. 2016. 
HORNES, K. L., BALICKI, M.

\section{CARACTERIZAÇÃO DO TORNADO OCORRIDO EM MARECHAL CÂNDIDO RONDON E QUATRO PONTES EM NOVEMBRO DE 2015}

OBSERVATÓRIO NACIONAL. Início da Primavera

2015. Disponível em: < http://www.on.br/conteudo/noticias/primaver a_11-09-2015.html> Acesso em: 19 jun. 2016.

PORTAL RONDON. Tornado em Marechal C. Rondon. Disponível em: < http://portalrondon.com.br/mobile_new/ver_n oticia_mobile.php?uid=42981> Acesso: 19 jun. 2016.

PERUZZO, J. A Física através de experimentos, física moderna e ciências espaciais. V III. Santa Catarina: Irani, 2013, p. 261.

PREFEITURA MUNICIPAL DE MARECHAL CANDIDO RONDON. Disponível em: < http://www.mcr.pr.gov.br/noticias/3861> Acesso em: 19 jun. 2016.

SILVA DIAS, M. A. F. Na increase in the number of tornado reports in Brazil. Weather Climate and Society, v. 3, n. 3, p.209-217, 2011.

SIMEPAR. Disponível em: <http://simepar.br/site/internas/conteudo/me teorologia/clima_estacoes/arquivos/primavera 2015.pdf> Acesso em: 17 dez. 2015.

VANGUARDIA. Tornado relatado no distrito de Irunã-Paraguai. Disponível em: < http://www.vanguardia.com.py/v1/index.php/ edicion-impresa/locales/item/37930-reportantornado-en-el-distrito-de-iru\%C3\%B1a>

Acesso em: 19 jun. 2016.

VEDOVATE; F. et al. Projeto Araribá: Geografia 8 ano. Editora Moderna; 3a edição. Pág. 76 a 78. São Paulo. 2010.

VESILIND, P. J. chasing tornadoes .National Geographic. p. 2-37, apr.2004

Vídeos (Frame):

https://www.youtube.com/watch?v=htpuZzO8j 9Y-figura 5 e 8; https://www.youtube.com/watch?v=leY6Ap3Cxc_figura 6 (esquerda)

https://www.youtube.com/watch?v=AxlyBHfO $9 W Q$ figura 6 (direita) 